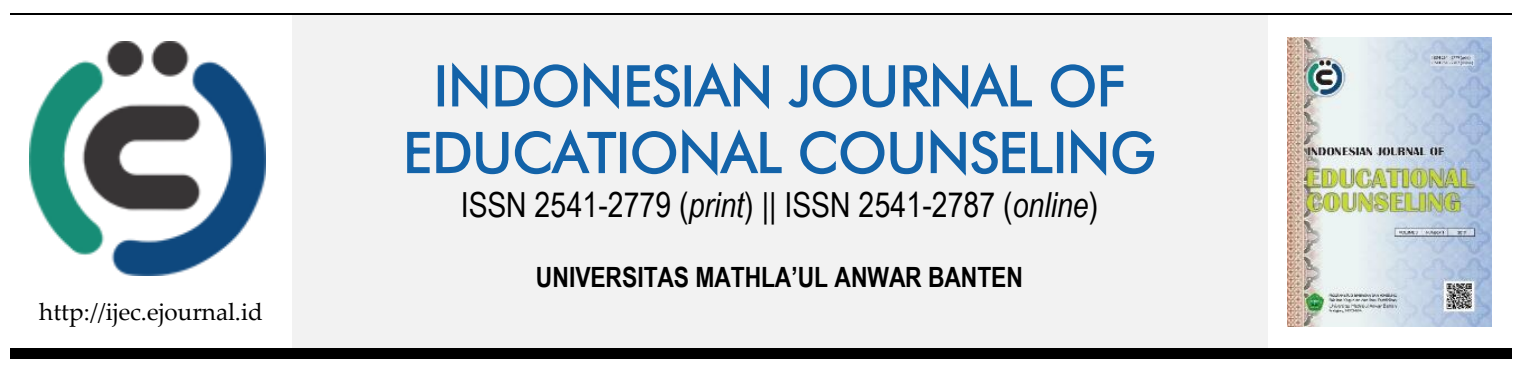

Theoretical/Conceptual Article

\title{
Mereduksi Kecemasan Siswa Melalui Konseling Cognitive Behavioral
}

\author{
I Putu Agus Apriliana' ${ }^{1}$ Kadek Suranata ${ }^{2}$, I Ketut Dharsana ${ }^{3}$ \\ 1, 2, 3 Universitas Pendidikan Ganesha
}

\begin{tabular}{ll}
\hline Article History & ABSTRACT \\
\hline Received: 10.08.2018 & Anxiety experienced by students at school can later affect their academic \\
Received in revised form: & success at school. For this reason, this study tries to describe students' anxiety \\
Accepted: 04.01 .2019 & and efforts to reduce them through cognitive behavioral counseling. Anxiety in \\
Available online: 24.01.2019 & students can be interpreted as a condition that is full of worries and fears, \\
& feeling depressed, not calm, feeling guilty, feeling insecure and chaotic-minded \\
& accompanied by physical tension to certain situations. The characteristics of \\
& students who experience anxiety are divided into three parts, namely physical, \\
& behavioral and cognitive. The steps to reduce student anxiety through cognitive \\
& behavioral counseling are 1) identifying and knowing the level of student \\
& anxiety, 2) carrying out cognitive behavioral counseling, namely: initiating \\
& counseling, discussing content in the session, checking the events of the \\
& previous week, Core counseling, assigning tasks for the next meeting, and \\
evaluating the session. Then, 3) Follow up. This article is expected to contribute & as a scientific literature in the field of guidance and counseling, especially for \\
school counselor in dealing with student anxiety through counseling services & using a cognitive behavioral approach at school.
\end{tabular}

Keywords: Counseling, Dialogue, Family, Solutions.

DOI: 10.30653/001.201931.46

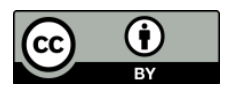

This is an open access article distributed under the terms of the Creative Commons Attribution 4.0 International License, which permits unrestricted use, distribution, and reproduction in any medium, provided the original work is properly cited. ๑ 2019 I Putu Agus Apriliana, Kadek Suranata, I Ketut Dharsana.

\section{PENDAHULUAN}

Siswa yang merasa cemas ketika melaksanakan kegiatan akademik di sekolah merupakan kondisi yang dapat mempengaruhi kesuksesannya di sekolah. Hasil penelitian yang dilakukan oleh Sharma dan Pandey (2017, p. 87) menjelaskan bahwa kecemasan berhubungan langsung dengan kehidupan sehari-hari siswa dan kecemasan ini dapat mempengaruhi tingkat prestasi akademiknya. Beberapa kecemasan yang dialami siswa di sekolah diantaranya siswa cemas dalam menentukan arah peminatannya (Wijaya, 2014, p. 84), cemas ketika bertanya di dalam kelas (Yusida, 2014), cemas menghadapi Ujian Nasional (Jannah, 2017, p. 156), cemas dalam belajar (Yanti, Erlamsyah, 
Zikra, \& Ardi, 284, p. 2013) dan kecemasan lainnya. Pada tingkat yang rendah, kecemasan ini masih dianggap sebagai gejala yang normal. Namun ketika tingkat kecemasan ini berlebihan, maka hal ini perlu mendapatkan perhatian dari pihak sekolah, mengingat dalam kondisi ini mereka tidak mampu mengatasinya sendiri (Leksono, 2013, p. 23).

Banyak hal sebenarnya yang mempengaruhi kecemasan siswa di sekolah. Secara spesifik, ada dua faktor yang mempengaruhi kecemasan siswa yaitu faktor internal dan eksternal (Rosmawati, 2017, p. 42). Kondisi fisik dan psikologis merupakan faktor internal yang mempengaruhi terjadinya kecemasan pada siswa. Selain itu, lingkungan juga dapat mempengaruhi terjadinya kecemasan pada siswa sebagai faktor eksternal. Maka dari itu, selain memperhatikan faktor internal, faktor eksternal juga perlu diperhatikan pada siswa yang mengalami kecemasan.

Mereduksi kecemasan siswa di sekolah, pada dasarnya dapat dilakukan dengan berbagai cara, salah satunya melalui layanan konseling yang diberikan oleh guru BK/Konselor. Berbagai pendekatan konseling sebenarnya dapat digunakan untuk mereduksi kecemasan siswa, salah satunya adalah pendekatan konseling cognitive behavioral. Pendekatan ini berfokus pada kognisi dan perilaku siswa, dimana merubah pikiran irasional dan melatih perilaku lebih adaptif. Dalam hal mereduksi kecemasan, diasumsikan bahwa pikiran irasional sebagai sumber dari kecemasan dan perilaku adaptif sebagai dampak dari adanya kecemasan tersebut. Maka dari itu, mereduksi kecemasan siswa menggunakan pendekatan cognitive behavioral ini berfokus pada pikiran dan perilaku.

Mengacu pada hal tersebut di atas, maka kajian ini mencoba menguraikan tentang kecemasan siswa dan mereduksinya melalui konseling cognitive behavioral. Artikel ini diharapkan dapat memberikan sumbangan sebagai literatur ilmiah dalam bidang bimbingan konseling. Secara khusus, hasil kajian ini dapat digunakan sebagai informasi kepada guru BK dalam menangani kecemasan siswa melalui layanan konseling menggunakan pendekatan cognitive behavioral di sekolah.

\section{KAJIAN LITERATUR}

Kecemasan adalah kondisi kejiwaan sesorang yang penuh khawatiran (aprehensi) dan ketakutan, dengan perasaan tertekan, tidak tenang, merasa bersalah, merasa tidak aman dan berpikiran kacau (emosi yang tidak menyenangkan) dimana ditandai dengan gejala-gejala jasmaniah seperti ketegangan fisik terhadap hal-hal yang mungkin saja akan terjadi (Azzahrain, 2005, p. 512; Jeffrey, Rathus, \& Greene, 2005, p. 163; Barlow \& Durand, 2006, p. 158; Triantoro, 2009, p. 49; Semiun, 2006, p. 321). Kecemasan bermanifestasi dalam banyak cara, termasuk rasa takut akan masa depan pada tingkat kognitif, ketegangan otot pada tingkat somatovisceral, dan penghindaran situasional pada tingkat perilaku (Dailey et al, 2014, p. 69).

Siklus kecemasan terletak di lingkungan tempat kejadian kemudian terhubung dengan kecemasan yang memprovokasinya. Dalam hal ini, latarbelakang kepercayaan dan asumsi mempengaruhi kecemasan seseorang. Namun pemicu kecemasan sebagai ancaman potensial dari lingkungan saling mempengaruhi terhadap siklus individu. Siklus individu diantaranya respon psikologis dalam perasaan cemas, perilaku dalam kondisi tetap aman, serta menapsirkan bahaya dari pikiran cemas saling mempengaruhi satu sama lain. Untuk itu, kondisi lingkungan yang diinternalisasikan oleh individu akan berhubungan dengan siklus individu tersebut, yang nantinya akan mempengaruhi 
tingkat kecemasan individu. Model umum kecemasan individu seperti dijelaskan pada Gambar 1.

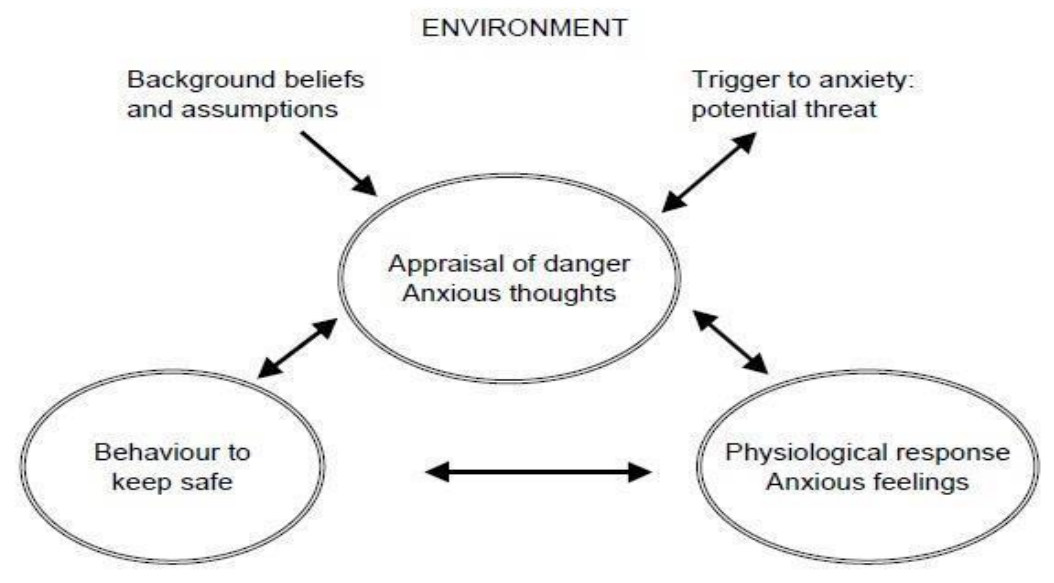

Gambar 1. Model Umum Kecemasan

(Sumber: Sanders \& Wills, 2003, p. 16)

Joebhaar (2003, p. 4) menilai bahwa peningkatan kecemasan yang terlalu pesat pada diri seseorang, merupakan akibat dari adanya tekanan-tekanan dalam kehidupan modern. Kecemasan yang berlebih memang akan membawa dampak buruk terhadap seseorang. Kecemasan dikatakan sebagai rangkaian pikiran, bisikan hati, dan bayangan negatif yang menerobos akal orang yang sadar dengan jalan memaksa (Yusuf, 2006, p. 141). Biasanya seseorang yang mengalami kecemasan cenderung tidak sadar, sering mengeluh, mudah tersinggung, sulit berkonsentrasi, mudah terganggu dan mengalami kesulitan untuk tidur (Gunarsa, 2008, p. 59). Menurut Santrock (2007, p. 529) kecemasan dikatakan berlebihan ketika kecemasan tersebut terus menerus terjadi dan berlangsung lama. Kecemasan pun mempengaruhi berbagai aspek aktivitas individu. Walker (dalam He, Deyuan 2018, p. 2) menjelaskan bahwa kecemasan memiliki hubungan dengan kinerja, yang diasumsikan seperti " $U$ " terbalik. Lebih lanjut dijelaskan bahwa, ketika kecemasan rendah maka kinerja juga akan rendah dan sebaliknya. Permasalahan akan timbul ketika, kecemasan individu berlebih tentunya akan mengakibatkan kinerjanya menjadi memburuk. Untuk itu, memiliki kecemasan merupakan hal yang normal pada setiap individu selama tingkat kecemasannya rendah.

\section{Kecemasan pada Siswa}

Kecemasan pada siswa dapat diartikan sebagai kondisi yang penuh khawatiran dan ketakutan, merasa tertekan, tidak tenang, merasa bersalah, merasa tidak aman dan berpikiran kacau yang disertai ketegangan fisik terhadap situasi tertentu. Sebenarnya, banyak hal yang dapat menyebabkan siswa menjadi cemas, salah satunya adalah ketika akan menghadapi ujian di sekolah. Ketakutan seorang siswa terhadap ujian, akan mengakibatkan terjadinya kecemasan dan tekanan yang berlebihan (Windura, 2008, p. 155). Jeffrey et al (2005, p. 163) menjelaskan bahwa ujian merupakan salah satu sumber kecemasan bagi siswa. Minimal sebelum ujian, siswa mempersiapkan diri terlebih dahulu meliputi intelektual (menguasai pelajaran yang akan diujikan), emosi dan kondisi fisik (Olivia, 2011, p. 7-8). Setidaknya langkah ini dilakukan agar kecemasan yang dialami siswa tidak berlebihan. Namun, ketika siswa mengalami kecemasan yang berlebihan, apalagi pada saat akan menghadapi ujian, tentunya hal ini akan berdampak pada 
terganggunya proses belajar siswa dan tentunya akan dapat menghambat pelaksanaan ujiannya (MGBK Provinsi DKI Jakarta, 2011, p. 20).

Soemanto (Supriyantini, 2010, p. 11) menjelaskan ciri-ciri kecemasan terbagi atas dua indikator yaitu indikator fisik dan psikis. Selanjutnya, Jeffrey et al (2005, p. 164) mengklasifikasikan secara lebih terperinci mengenai ciri-ciri siswa yang mengalami kecemasan sebagai berikut:

1) Secara fisik meliputi gugup, gelisah, anggota tubuh bergetar atau gemetar, berkeringat, sulit berbicara, sulit bernafas, mulut atau kerongkongan terasa kering, jantung berdebar atau berdetak kencang, lemas, mati rasa, merasa pusing, selalu buang air kecil, dan adanya perasaan sensitif.

2) Secara perilaku meliputi tindakan menghindar, melekat atau ketergantungan, dan terguncang.

3) Secara kognitif meliputi khawatir tentang sesuatu, adanya keyakinan bahwa sesuatu yang mengerikan akan segera terjadi, merasa takut kehilangan kontrol diri, adanya perasaan terganggu atau ketakutan akan sesuatu yang terjadi di masa depan, takut akan ketidakmampuan mengatasi masalah, serta merasa sulit untuk memfokuskan pikiran (berkonsentrasi), dan memiliki pemikiran bahwa semuanya tidak dapat dikendalikan lagi.

\section{Teori Cognitive behavioral}

Teori cognitive behavioral memandang bahwa perkembangan manusia didasarkan pada pengalaman belajar yang berbeda pada masing-masing individu, pengalaman unik yang diberikan oleh lingkungan dan pemahaman kognisi individu terhadap dunia (Capuzzi \& Stauffer, 2016, p. 230). Lebih lanjut, Aaron T. Beck menjelaskan bahwa sifat dasar manusia berfokus pada kognisinya, dimana dalam hal ini lebih lanjut dijelaskan bahwa 1) komunikasi internal individu dapat diakses melalui introspeksi, 2) keyakinan individu memiliki makna yang sangat pribadi, dan 3) interpretasi ini hanya dapat ditemukan oleh individu sendiri bukan oleh orang lain/konselor (Chao, 2015, p. 166). Pada prinsipnya, model dari pendekatan cognitive behavioral ini sesuai dengan Gambar 2.

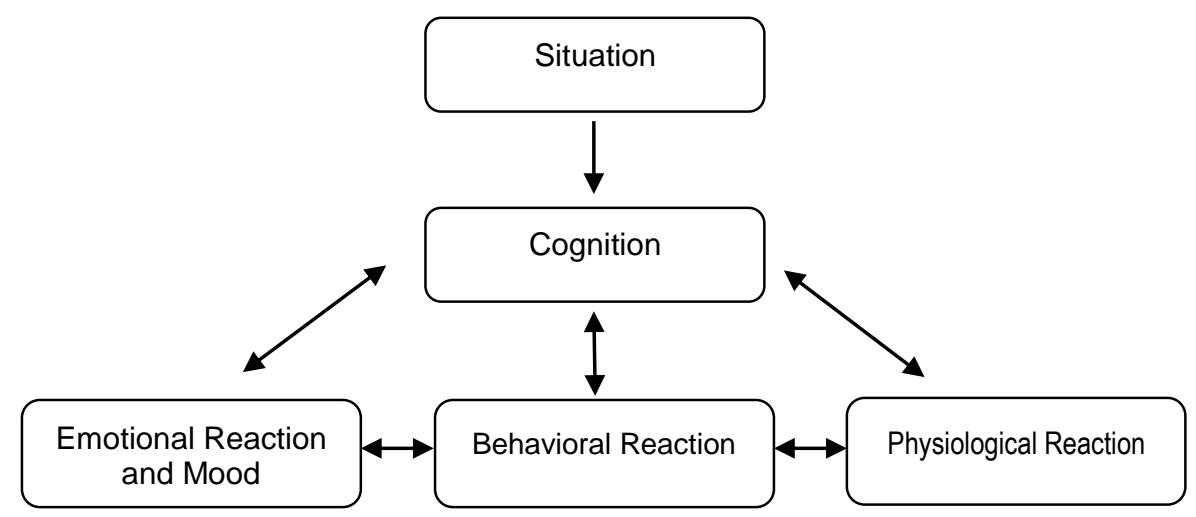

Gambar 2. Basic Cognitive behavioral Model

(Sumber: Wenzel, et al, 2016, p. 26)

Pada Gambar 2. dapat diketahui bahwa pendekatan cognitive behavioral ini berfokus pada kognisi. Reaksi emosi, reaksi perilaku dan reaksi psikologis individu memiliki hubungan dengan kognisi (saling mempengaruhi). Di sisi lain, situasi (kondisi lingkungan) juga mempengaruhi kognisi individu. Kendall (dalam Joyce-Beaulieu \& 
Sulkowski, 2015, p. 27) menjelaskan bahwa model pendekatan cognitive behavioral ini mengarhakan yaitu bagaimana kognisi individu memediasi emosinya dan bagaimana respon perilaku individu terhadap situasi, yang tentunya akan mempengaruhi dalam waktu jangka pendek dan bahkan jangka panjang.

Prinsip utama dari pendekatan cognitive behavioral ini adalah: 1) Mengakses pikiran irasional dan maladaptif konseli, 2) Mengarahkan konseli menjadi lebih adaptif atau lebih berpikir rasional dan teach verbal internal strategi coping instruksional, 3) mendukung konseli ketika mereka menerapkan hal ini pertama kalinya dan mengembangkan kemampuan dalam kehidupan mereka (Flanagan \& Flanagan, 2015, p. 275).

Pendekatan cognitive behavioral ini tersusun berdasarkan model psycho-educational, menekankan peran pekerjaan rumah, tempat tanggungjawab pada konseli untuk menganggap peran aktif keduanya (konselor dan konseli) dan diluar sesi konseling, serta mengambil dari berbagai strategi kognisi dan perilaku yang membawa perubahan (Corey, 2009, p. 275). Pendekatan ini digunakan dalam berbagai macam kondisi psikologis seperti depresi, masalah kecemasan, masalah kepribadian, masalah penyalahgunaan obat, eating disorder, dan couple's distress (Farmer \& Chapman, 2016, p. 3).

Pendekatan cognitive behavioral ini biasanya memerlukan satu atau kombinasi dari prinsip: 1) Koreksi keyakinan kontra produktif atau interpretasi; 2) Belajar dan menguji cara alternatif untuk menafsirkan pengalaman seseorang; 3) Membantu konseli untuk mengubah bagaimana dia berperilaku dalam situasi ini; 4) Belajar menerima dan menguji cara baru untuk memahami diri sendiri, pengalaman seseorang dan asumsi tentang masa depan (Ost \& Skaret, 2013, p. 99).

\section{DISKUSI}

Tujuan konseling cognitive behavioral ini adalah untuk menghapuskan pandangan konseli tentang self-defeating dan membantu mereka menjadi lebih toleran dan terlihat rasional. Lebih lanjut dijelaskan bahwa, konseli diajarkan bagaimana mereka menggabungkan kepercayaan self-defeating, bagaimana mereka memelihara cara berpikir yang salah ini, apakah mereka bisa melakukan untuk mengurangi cara berpikir ini, dan bagaimana mereka bisa mengajarkan diri mereka sendiri cara baru untuk berpikir bahwa mereka sendiri akan memimpin perubahan berdasarkan cara mereka sendiri tentang perilaku dan perasaannya (Corey, 2013, p. 155).

Melakukan proses assessment terhadap konseli merupakan bagian yang tidak dapat terpisahkan dalam proses konseling cognitive behavioral (Wenzel et al, 2016, p. 16). Proses assessment ini selalu diawali dengan intake interview (Hofmann \& Asmundson, 2017:22). Dalam proses ini, konselor menggali informasi terhadap gejala-gejala mencakup perasaan, kognisi dan perilaku yang dialami oleh konseli. (Short \& Thomas, 2015, p. 378) Sesi dalam konseling cognitive behavioral yaitu:

1) Mendiskusikan isi dalam sesi (5 menit)

Diskusi akan mencakup apa yang dipikirkan konselor dan konseli akan berguna untuk bekerja selama sesi itu.

2) Mengecek minggu sebelumnya (10 menit)

Memperbaharui tentang apa yang telah terjadi minggu lalu dan bagaimana konseli dikelola dengan tugas pekerjaan rumah sebelumnya.

3) Isi utama (25 menit),

Pekerjaan tertentu diputuskan pada awal sesi dan termasuk penerapan teknik CBT. 
4) Menetapkan tugas untuk minggu depan (5 menit)

Pekerjaan rumah yang disepakati oleh konselor dan konseli. CBT mewajibkan konseli untuk mengerjakan tugas diantara sesi-sebagai proses konseling, berlanjut konseli harus lebih bertanggungjawab untuk menetapkan tugas dan mengelola proses perubahan.

5) Mengevaluasi sesi (5 menit)

Memeriksa apa yang dipikirkan konseli berguna dan apa yang tidak membantu selama sesi ini.

Teknik-teknik konseling dalam pendekatan cognitive behavioral ini adalah Self-Talk, Reframing, Thought Stopping, Cognitive Restructuring, Rational Emotive Behavior Therapy (REBT), Bibliotherapy, Journaling, Systematic Desensitization, dan Stress Inoculation Training (Erford, 2015, pp. 116-173).

Temuan yang dihasilkan oleh Wergeland et al (2014, p. 1) menjelaskan bahwa pendekatan cognitive behavioral efektif menangani remaja yang mengalami kecemasan. Pendekatan cognitive behavioral ini digunakan untuk membantu penderita gangguan kecemasan dalam mengubah makna ketakutan dan gejala mereka, dan untuk membingkai kembali keyakinan terdistorsi yang terkait dengannya emosi maladaptif seperti rasa bersalah, malu, malu dan marah (Alladin, 2016, p. 34). Dalam hal ini, pendekatan cognitive behavioral digunakan untuk mereduksi kecemasan yang dialami oleh siswa. Banyak hal sebenarnya yang menyebabkan siswa merasa cemas di sekolah, salah satunya adalah ketika menghadapi ujian. Beberapa hal yang perlu diperhatikan oleh guru BK/Konselor dalam mengaplikaskan pendekatan cognitive behavioral ini dalam mereduksi kecemasan siswa sebagai berikut.

Pertama, mengidentifikasi gejala-gejala kecemasan siswa dan mengetahui tingkat kecemasan yang dialaminya. Tentu dalam hal ini, guru BK/Konselor harus memiliki datadata berupa data observasi, instrumentasi, wawancara dan data lainnya untuk mendukung proses analisis permasalahan siswa (dalam hal ini mengenai kecemasan). Namun perlu diketahui bahwa, gejala kecemasan pada siswa merupakan hal yang wajar ketika kecemasannya masih dalam tingkat yang rendah. Setelah guru BK/Konselor memiliki data-data yang lengkap, selanjutnya melakukan strategi penerapan pendekatan cognitive behavioral baik melalui konseling individu maupun konseling kelompok, tergantung dari jumlah siswa yang mengalami masalah kecemasan.

Kedua, mengaplikasikan pendekatan cognitive behavioral dalam konseling individu untuk mereduksi kecemasan siswa, tahapan yang dilakukan, yaitu:

1) Memulai Konseling (2 menit)

Proses rapport yang baik dapat mempengaruhi keberlanjutan dan keberhasilan proses konseling (Anwar, 2014, p. 51). Selanjutnya melakukan proses intake interview untuk menggali informasi terhadap gejala-gejala mencakup perasaan, kognisi dan perilaku yang dialami oleh konseli. Guru BK/Konselor diharapkan tidak memberikan penilaian tertentu terhadap konseli (Prayitno, 2012, p. 15).

2) Mendiskusikan isi dalam sesi (5 menit)

Dalam hal ini, guru BK/Konselor harus menciptakan kondisi yang membuat konseli bersedia terlibat secara afeksi dan kognitif dalam setiap sesinya (Lubis, 2011, p. 59). Sesi ini juga mendiskusikan kesepakatan bersama (konselor \& konseli) terkait tujuan dari konseling ini dilakukan. 
3) Mengecek kejadian minggu sebelumnya (10 menit)

Jika ini memang pertemuan pertama, maka guru BK/Konselor boleh tidak melakukan sesi ini. Namun hal ini sangat penting dilakukan jika ini merupakan pertemuan lanjutan dari pertemuan sebelumnya. Tentu dalam proses ini untuk mengetahui perkembangan kondisi konseli.

4) Inti Konseling (25 menit)

Dalam sesi ini, memberikan langkah-langkah psikoedukasi dan restrukturisasi kognisi dengan menggunakan teknik-teknik cognitive behavioral. Teknik yang akan digunakan merupakan kesepakatan bersama antara guru BK/Konselor dengan konseli.

5) Menetapkan tugas untuk pertemuan selanjutnya (5 menit)

Terkait tugas yang akan dilakukan oleh konseli, mengacu pada teknik yang telah diaplikasikan dalam sesi inti konseling. Teknik ini berkelanjutan dilakukan oleh konseli sebagai bentuk tanggungjawab terhadap perubahan yang terjadi pada dirinya. Dalam hal ini, kesepakatan antara guru BK/Konselor dengan konseli masih sangat diharapkan.

6) Mengevaluasi sesi (5 menit)

Setelah semua sesi selesai, selanjutnya mengevaluasi setiap sesi yang telah dilakukan.

Tentu indikator dari proses evaluasi ini adalah sejauhmana sasaran/tujuan dari konseling ini telah tercapai (Lesmana, 2013:100).

Ketıga, tindak lanjut. Setelah proses konseling selesai dilaksanakan, maka konselor tetap melakukan pemantauan terhadap perkembangan keberhasilan treatment. Hal ini dilakukan oleh guru BK/Konselor agar ketika keberhasilan treatment tidak tercapai dapat dengan segera melakukan tindakan penanganan lainnya yang lebih efektif.

Secara umum, tahapan tersebut di atas merupakan langkah-langkah yang dilakukan oleh guru BK/Konselor ketika mengaplikasikan pendekatan cognitive behavioral dalam proses konseling untuk mereduksi kecemasan siswa di sekolah. Tentunya tahapan tersebut tidak mutlak harus sesuai dengan tahapan tersebut, namun secara garis besar proses pelaksanaannya seperti yang sudah dijelaskan di atas.

\section{SIMPULAN}

Kecemasan pada siswa dapat diartikan sebagai kondisi yang penuh khawatiran dan ketakutan, merasa tertekan, tidak tenang, merasa bersalah, merasa tidak aman dan berpikiran kacau yang disertai ketegangan fisik terhadap situasi tertentu. Ciri-ciri siswa yang mengalami kecemasan terbagi menjadi tiga bagian yaitu secara fisik, perilaku dan kognitif. Upaya mereduksi kecemasan siswa dapat dilakukan oleh guru BK/Konselor melalui konseling cognitive behavioral. Langkah-langkahnya yaitu 1) mengidentifikasi gejala-gejala kecemasan siswa dan mengetahui tingkat kecemasan yang dialaminya, 2) melaksanakan konseling cognitive behavioral yaitu dengan memulai Konseling (2 menit), mendiskusikan isi dalam sesi (5 menit), mengecek kejadian minggu sebelumnya (10 menit), melaksanakan inti konseling (25 menit), menetapkan tugas untuk pertemuan selanjutnya (5 menit), dan mengevaluasi sesi (5 menit). Setelah pelaksanaan konseling selesai, selanjutnya melakukan tahap 3) Tindak lanjut. Untuk itu, ketika konseling cognitive behavioral ini diaplikasikan, maka diketahui berpotensi untuk mereduksi kecemasan siswa. 


\section{REFERENSI}

Alladin, A. (2016). Integrative CBT for anxiety disorders, an evidence-based approach to enhancing cognitive behavioural therapy with mindfulness and hypnotherapy. New Jersey: John Wiley \& Sons.

Anwar, Z. (2014). Praktik konseling. Malang: Universitas Muhammadiyah Malang.

Azzahrain, M. B. S. (2005). Konseling terapi. Jakarta: Gema Insani Press

Barlow, D., \& Durand, M. (2006). Psikologi abnormal. Yogyakarta: Penerbit Pustaka Pelajar.

Capuzzi, D., \& Stauffer, M. D. (2016). Counseling and psychotherapy: Theories and interventions. New Jersey: John Wiley \& Sons.

Chao, R. C. L. (2015). Counseling psychology: An integrated positive psychological approach. New Jersey: John Wiley \& Sons.

Corey, G. (2009). Theory and practice of counseling and psychotherapy (Eighth edition). Thomson, GA: Thomson Higher Education.

Corey, G. (2013). Case approach to counseling and psychotherapy (Eighth edition). USA: Books/Cole.

Dailey, S. F., Gill, C. S., Karl, S. L., \& Minton, C. A. B. (2014). DSM-5, Learning companion for counselors. USA: American Counseling Association.

Erford, B. T. (2015). Forty techniques every counselor should know (Second edition). London: Pearson Education.

Farmer, R. F., \& Chapman, A. L. (2016). Behavioral interventions in cognitive behavior therapy, practical guidance for putting theory into action (Second edition). Washington, DC: American Psychological Association.

Flanagan, J. S., \& Flanagan, R. S. (2015). Counseling and Psychotherapy Theories in Context and Practice. Skills, Strategies and Techniques (Second edition). Canada: John Wiley \& Sons.

Ost, L. G., \& Skaret, E. (Eds.). (2013). Cognitive behavioral therapy for dental phobia and anxiety. New Jersey: John Wiley \& Sons.

Gunarsa, D. S. (2008). Psikologi praktis: Anak, remaja, dan keluarga. Jakarta: BPK Gunung Mulia.

He, D. (2018). Foreign language learning anxiety in china, theories and applications in english language teaching. Singapore: Spinger Nature. 
Hofmann, S. G. \& Asmundson, G. J. G. (2017). The science of cognitive behavioral therapy. United Kingdom: Academic Press an imprint of Elsevier.

Joyce-Beaulieu, D., \& Sulkowski, M. L. (2015). Cognitive behavioral therapy in K-12 school settings: a practitioner's toolkit. New York: Springer Publishing Company.

Leksono, T. (2013). Stategi intervensi konseling untuk mengatasi kecemasan siswa. Jurnal Konseling dan Pendidikan, 1(1), 23-26.

Jannah, N. (2017). Pengaruh Zikir al-Ma'tsurat dan Terjemahannya Terhadap Penurunan Kecemasan Siswa Menghadapi Ujian Nasional. Jurnal Studia Insania, 5(2), 155-173.

Jeffrey, N., Rathus, A. S., \& Greene B. (2005). Psikologi abnormal. Jakarta: Penerbit Erlangga.

Joebhaar, M. (2003). Kecemasan, bagaimana mengatasi penyebabnya. Jakarta: Pustaka Populer Obor.

Lesmana, J. M. (2013). Dasar-dasar konseling. Jakarta: Universitas Indonesia (UI-Press).

Lubis, N. L. (2011). Memahami dasar-dasar konseling, dalam teori dan praktik. Jakarta: Kencana Prenada Media Group.

MGBK Provinsi DKI Jakarta. (2011). Bahan dasar untuk pelayanan konseling pada satuan menengah. Jakarta: Gramedia Widiasarana Indonesia.

Olivia, F. (2011). Tools for study skills, teknik ujian efektif. Jakarta: Elex Media Komputindo.

Prayitno. (2012). Dasar dan dinamika hubungan konseling. Padang: Pendidikan Profesi Konselor Universitas Negeri Padang.

Rosmawati. (2017). Penerapan Layanan Konseling untuk Mengatasi Kecemasan Siswa. JURKAM: Jurnal Konseling Andi Matappa, 1(1), 39-45.

Sanders, D., \& Wills, F. (2003). Counseling for anxiety problems (Second edition). London: SAGE Publications.

Santrock. J. W. (2007). Perkembangan masa hidup. Jakarta: Erlangga.

Semiun, Y. (2006). Teori kepribadian dan terapi psikoanalitik Freud. Yogyakarta: Kanisius.

Sharma, G., \& Pandey, D. (2017). Anxiety, depression, and stress in relation to academic achievement among higher secondary school students. The International Journal of Indian Psychology, 4(2), 82-89.

Short, F., \& Thomas, P. (2015). Core approaches in counselling and psychotherapy. New York: Routledge.

Wenzel, A., Dobson, K. S., \& Hays, P. A. (2016). Cognitive behavioral therapy techniques and strategies. Washington, DC: American Psychological Association. 
Wergeland, G. J. H., Fjermestad, K. W., Marin, C. E., Haugland, B. S. M., Bjaastad, J. F., Oeding, K., Bjelland, I., Silverman, W. K., Ost, L. G., Havik, O. E., \& Heiervang, E. R. (2014). An effectiveness study of individual vs. group cognitive behavioral therapy for anxiety disorders in youth. Behaviour Research and Therapy, 57, 1-12.

Wijaya, R. S. (2014). Model konseling kelompok eksistensial humanistik untuk mengurangi kecemasan siswa menentukan arah peminatan SMA Negeri Semarang. Jurnal Bimbingan Konseling, 3(2), 83-89.

Windura, S. (2008). Brain management series for learning strategy, be an absolute genius!: Panduan praktis learn how to learn sesuai cara kerja alami otak. Jakarta: Elex Media Komputindo.

Yanti, S., Erlamsyah, E., Zikra, Z., \& Ardi, Z. (2013). Hubungan antara Kecemasan dalam Belajar dengan Motivasi Belajar Siswa. Konselor, 2(1), 283-288.

Yusida, L. P., Ibrahim, I., \& Said, A. (2016). Hubungan Self-Confidence dengan Kecemasan Siswa Ketika Bertanya di dalam Kelas. Konselor, 3(4), 132-138.

Yusuf, A. U. (2006). Menuju puncak prestasi tanpa batas. Jakarta: Gema Insani Press. 